\title{
Prevalence, infection intensity and associated factors of soil transmitted helminths among primary school children in Gurage zone, South Central Ethiopia: a cross-sectional study design
}

\author{
Habtamu Weldesenbet ${ }^{1 *}$, Abdulsemed Worku² and Teha Shumbej ${ }^{1}$
}

\begin{abstract}
Objective: The aim of this study was to determine the prevalence of soil transmitted helminthes among primary school children. School based cross-sectional study design was employed. A total of six hundred study subjects were selected by a multistage sampling method. Fresh stool specimens were collected using clean, dry and wide mouthed labeled stool cups. It was processed by Kato-Katz technique. The data were analyzed using SPSS version 20 and p-value $<0.05$ was considered statistically significant.

Result: The overall prevalence of soil transmitted helminthes was 57 (9.5\%). Hookworm was the most prevalent helminthes species isolated (4.2\%) followed by A. lumbricoide (3\%). The prevalence of Taenia species, T. trichiura, H. nana and E. vermicularis were; $1.2 \%, 0.5 \%, 0.7 \%$ and $0.8 \%$ respectively. The prevalence of the Soil transmitted helminthes infection was low and all cases of Soil transmitted infections in this study were with low infection intensity. This might be due to the preventive chemotherapy given to the school children.
\end{abstract}

Keywords: Soil transmitted helminthes, Intestinal parasites, School children, Gurage zone, Prevalence, Ethiopia, Wolkite

\section{Introduction}

Intestinal helminthes infections are among the most common infections in school children. Globally, an estimated number of 878 million school aged children and 386 million Preschool aged children are at risk [1]. The prevalence of soil transmitted helminthes $(\mathrm{STH})$ infection is mainly attributed to their chronic and insidious impact on the health quality of life those infected rather than the mortality they cause. Heavy infection of STH impairs physical growth and brain development, and are the causes of micronutrient deficiency including iron deficiency anemia leading to poor school performance

\footnotetext{
*Correspondence: hweldesenbethadgu@gmail.com

${ }^{1}$ Department of Medical Laboratory Science, College of Medicine and Health Sciences, Wolkite University, P.O. Box 07, Wolkite, Ethiopia Full list of author information is available at the end of the article
}

and reduced work productivity in adults and adverse pregnancy outcomes [2]. The soil transmitted helminthes strategic plan 2011-2020 has outlined four miles stones for global control of soil-transmitted helminthes infection [3]. School children aged 5-15 years suffer the highest infection rate and worm burden due to poor personal hygiene and low sanitation $[4,5]$.

Soil-transmitted helminthes are highly abundant in Ethiopia; hookworm infects 11 million people, thus Ethiopia bears $5.6 \%$ which was the third highest burden in Sub-Saharan Africa and T. trichiura, with 21 million people, which was the 4th highest (13\%) of the diseases burden in Sub-Saharan Africa [6, 7]. Similarly A. lumbricoide estimated to infect 26 million people which were the second highest burden (15\%) of the overall burden in SubSaharan Africa $[8,9]$. 
Study conducted in Babile Town, Ethiopia also showed Prevalence of hookworm infection rate was significantly lower in children who wore shoes [10]. Study conducted in Bahir Dar, Ethiopia also showed having dirty hands' fingernail and untrimmed hands' fingernail were positively associated with the overall prevalence of intestinal helminthes infection [11].

In the 2013-2014 Ethiopian national mapping of infections of soil transmitted helminths and association with School Water, Sanitation, and Hygiene was assessed alongside infection intensity in school children, and the result have shown that $A$. lumbricoides, T. trichiura, and hookworm were $13.3 \%, 7.8 \%$, and $7.4 \%$ respectively. At least one case of each of those helminths was found in $75.4 \%, 51.7 \%$, and $52.0 \%$ of these schools, respectively [12].

Preventive Chemotherapy treatment was began in the study area since 2015. Three rounds of preventive chemotherapy treatments were given in the study area till 2017. Even though there was no study done in the study area before the preventive chemotherapy treatment began, the national mapping done 2013/2014 has shown that prevalence of soil transmitted helminths in the country was high. Therefore it is important to determine the prevalence and infection intensity of soil transmitted helminths to see preventive chemotherapy treatment outcomes. Therefore, this study was intended to investigate the prevalence, infection intensity and associated factors of Soil transmitted helminths among primary school children in Gurage zone, South Central Ethiopia after three rounds of preventive chemotherapy treatment.

\section{Main text}

\section{Methods and materials} Study design and area

A cross sectional study design was performed among primary school children in Gurage zone to estimate the prevalence of soil transmitted helminthes and associated factors. There was lack of water supply in the study area and many people in the community, including school children were exposed for soil transmitted helminthes due to poor personal hygiene.

\section{Sample size and sampling technique}

Three districts were selected using purposive method based on previous data of soil transmitted helminthes. From the three districts six schools were selected based on population density, ecological zone and risk factors. Proportionate sample was allocated to each school based on school population density. In each school the sample was distributed according to the number of the students in each grade and section. The registration list was used as the sampling frame. The required sample size for this study was estimated using the general formula for single population proportion [13] and considering 36.7\% [14] prevalence rate in the population, 95\% confidence level and $5 \%$ margin of error with 1.5 design effect. Accordingly the following formula was applied:

$$
\begin{aligned}
\mathrm{n} & =\frac{\mathrm{Z}^{2} \mathrm{P}(1-\mathrm{P})}{\mathrm{d}^{2}} \\
& =(1.96)^{2} 0.37(1-0.37) /(0.05)^{2} \\
& =358 * 1.5=537 .
\end{aligned}
$$

Assumptions: $\mathrm{P}=$ prevalence rate, $\mathrm{d}=$ margin of sampling error tolerated between the sample and population $5 \%, \alpha=$ critical value at $95 \%$ confidence interval of certainty (1.96), $n=$ sample size, $Z=95 \%$ confidence level.

Considering $10 \%$ for anticipated non-response rate and design effect of 1.5, the sample size is 600 .

\section{Inclusion criteria}

The participants whose guardian or parent signed a written informed consent and all children who were available and registered in their school during the study period and who gave stool sample were included in the study.

\section{Exclusion criteria}

Participants who were on anti-helminthic drug or treatment within 2 weeks prior to data collection and study subjects who were unable to provide a stool specimen at the time of sampling were excluded from the study.

\section{Data collection and processing \\ Socio-demographic data and risk factor assessment of study participants}

The questionnaire was prepared in English and translated to local language Guragegna and checked for fitness. Pre-test was done in 5\% of school children that were not included in the study. Appropriate Correction was made according to the result. Parents or guardian of the school children participated in the study were interviewed with the pre-tested questionnaire to collect the demographic data and associated risk factors.

\section{Parasitological techniques}

Clean, dry and tightly screwed stool cup was given to each study subjects. Sufficient amount of stool sample was collected from each student. The stool samples were processed by Medical Laboratory Technologists using the standard Kato-Katz technique [15].

In the Kato-Katz technique feces were pressed through a mesh screen to remove large particles. A portion of the sieved sample was then transferred to the hole of a template on a slide. After filling the hole, the template was 
removed and the remaining sample (approx. $50 \mathrm{mg}$ ) was covered with a piece of cellophane soaked in glycerol (glycerine). The glycerol 'clears' the faecal material from the eggs.

A microscopic examination was done to identify the parasites and infection intensity within $30 \mathrm{~min}$ of collection. The slide smears were examined using $10 \times$ and $40 \times$ objectives. The eggs were then counted and the number was calculated per gram (g) of feces to determine the intensity of the infection in each slide according to the WHO bulletin in 1993 [16].

\section{Data quality control}

Training was given to data collectors and Medical Laboratory technologists before the start of data collection. The questionnaire was checked for completeness and any incomplete questionnaire was corrected under supervision during data collection. Two slides were prepared from each sample. The slides were examined by two Medical Laboratory Technologists independently first with Low $(10 \times)$ objective followed by the middle $(40 \times)$ objective. Ten percent of the samples were randomly selected and re-checked by Senior Medical Laboratory Technologists.

\section{Data analysis and Interpretation}

The data were entered into SPSS version 20.0 for statistical analysis. The demographic data were described by descriptive statistics. The prevalence of soil transmitted helminthes was determined. Bivariate analysis was done and $95 \%$ confidence interval was calculated. The p-value of $<0.25$ in bivariate was taken to build adjusted binary logistic regression analysis. Logistic regression model with backward elimination was taken. Variables that were associated with soil transmitted helminthes at $<0.05$ were retained in the model.

\section{Result}

A total of 600 school children were included in this study. From these study subjects, 349 (58.17\%) were males and $251(41.83 \%)$ were females. The mean age of the study subjects was 10.48 years with a minimum of 4 years and maximum of 17 years (Table 1 ).

The overall prevalence of soil transmitted helminthes among school children was $57(9.5 \%)$, among them $35(10.03 \%)$ were males and $23(9.16 \%)$ were females. Higher prevalence was observed among males than females $(10.03 \%$ vs. $9.16 \%)$. With regard to specific age group, school children in the age group of $<6$ years were more infected than 6-10 years and 11-15 years of age groups of the study subjects, $22.22 \%, 10.37 \%$ and $9.09 \%$ respectively. None of the study subjects with age group
Table 1 Socio-demographic characteristics of study participants in Gurage zone southern Ethiopia (January to December 30, 2017) $(n=600)$

\begin{tabular}{|c|c|c|}
\hline & Frequency & Percent (\%) \\
\hline \multicolumn{3}{|l|}{ Gender of the child } \\
\hline Male & 349 & 58.17 \\
\hline Female & 251 & 41.83 \\
\hline Total & 600 & 100.0 \\
\hline \multicolumn{3}{|l|}{ Age } \\
\hline Mean of age & 10.48 & \\
\hline Minimum age & 4 & \\
\hline Maximum age & 17 & \\
\hline \multicolumn{3}{|l|}{ Age group of children } \\
\hline$<6$ & 9 & 1.5 \\
\hline $6-10$ & 299 & 49.8 \\
\hline $11-15$ & 264 & 44.0 \\
\hline$>15$ & 28 & 4.7 \\
\hline Total & 600 & 100.0 \\
\hline \multicolumn{3}{|l|}{ Residence of the child } \\
\hline Urban & 317 & 52.83 \\
\hline Rural & 283 & 47.27 \\
\hline Total & 600 & 100.0 \\
\hline \multicolumn{3}{|c|}{ Mother's highest level of education } \\
\hline Illiterate & 277 & 46.17 \\
\hline Informal education & 1 & 0.17 \\
\hline Primary 1_8 & 281 & 46.83 \\
\hline Secondary 9_12 & 31 & 5.17 \\
\hline Diploma & 10 & 1.66 \\
\hline Total & 600 & 100.0 \\
\hline \multicolumn{3}{|l|}{ Districts of the child } \\
\hline Abeshge & 297 & 49.50 \\
\hline Cheha & 103 & 17.17 \\
\hline Kebena & 200 & 33.33 \\
\hline Total & 600 & 100.0 \\
\hline \multicolumn{3}{|l|}{ Ethnicity of the child } \\
\hline Gurage & 265 & 44.17 \\
\hline Amhara & 260 & 43.33 \\
\hline Oromo & 54 & 9.0 \\
\hline Tigre & 3 & 0.5 \\
\hline Other & 18 & 3.0 \\
\hline Total & 600 & 100.0 \\
\hline
\end{tabular}

of $>15$ years have soil transmitted helminthes infection (Table 2). Hookworm was the highest soil transmitted helminthes infection (4.2\%) followed by A. lumbricoide (3\%) while Taenia species, E. vermicularis, H. nana and T. trichiura were $1.2 \%, 0.8 \%, 0.7 \%$ and $0.5 \%$ respectively (Additional file 1: Table S1).

All cases of the soil transmitted helminthes infection among school children were with light infection, such as Hookworm, E. vermicularis, Taenia species, A. 
Table 2 The overall prevalence of the soil transmitted helminthes and the significance of associated risk factors among school children in Gurage zone southern Ethiopia (January to December 30, 2017) $(n=600)$

\begin{tabular}{|c|c|c|c|c|}
\hline \multirow[t]{2}{*}{ Variables } & \multicolumn{3}{|c|}{ Soil transmitted helminthes } & \multirow[t]{2}{*}{ p-value } \\
\hline & No & Yes & Total & \\
\hline \multicolumn{5}{|l|}{ Gender } \\
\hline Male & $314(89.97 \%)$ & $35(10.03 \%)$ & $349(58.17)$ & $>0.05$ \\
\hline Female & $228(90.84 \%)$ & $23(9.16 \%)$ & $251(41.83 \%)$ & 1 \\
\hline \multicolumn{5}{|l|}{ Age group } \\
\hline$<6$ & $7(77.78 \%)$ & $2(22.22 \%)$ & $9(1.5 \%)$ & 1 \\
\hline $6-10$ & $268(89.63 \%)$ & $31(10.37 \%)$ & 299 (49.83\%) & $>0.05$ \\
\hline $11-15$ & $240(90.91 \%)$ & $24(9.09 \%)$ & $264(44.0 \%)$ & $>0.05$ \\
\hline$>15$ & $28(100 \%)$ & $0(0 \%)$ & $28(4.67 \%)$ & $>0.05$ \\
\hline \multicolumn{5}{|l|}{ Districts } \\
\hline Abeshege & $271(91.25 \%)$ & $26(8.75 \%)$ & 297 (49.50\%) & $>0.05$ \\
\hline Kebena & $182(91.24 \%)$ & $18(8.76 \%)$ & $200(33.33 \%)$ & $>0.05$ \\
\hline Cheha & $88(86.27 \%)$ & $14(13.73 \%)$ & $103(17.00 \%)$ & 1 \\
\hline \multicolumn{5}{|c|}{ Mother's education } \\
\hline Illiterate & $254(91.67 \%)$ & $23(8.30 \%)$ & $277(46.17 \%)$ & $>0.016$ \\
\hline Informal & $1(100 \%)$ & $0(0 \%)$ & $1(0.17 \%)$ & $>0.05$ \\
\hline Primary & $249(89.89 \%)$ & $31(11.07 \%)$ & $280(46.67 \%)$ & $>0.05$ \\
\hline Secondary & $33(100 \%)$ & $0(0 \%)$ & $33(5.5 \%)$ & $>0.05$ \\
\hline University & $6(66.67 \%)$ & $3(33.33 \%)$ & $9(1.5 \%)$ & 1 \\
\hline \multicolumn{5}{|c|}{ Play in the soil } \\
\hline Yes & $496(90.18 \%)$ & $54(9.82 \%)$ & $550(91.67 \%)$ & $>0.05$ \\
\hline No & 45 (91.49\%) & $5(8.51 \%)$ & $50(8.33 \%)$ & 1 \\
\hline \multicolumn{5}{|c|}{ Untrimmed finger } \\
\hline Yes & $257(91.14 \%)$ & $27(8.86 \%)$ & $284(47.33 \%)$ & $>0.05$ \\
\hline No & $283(89.56 \%)$ & $33(10.44 \%)$ & $316(52.67 \%)$ & 1 \\
\hline \multicolumn{5}{|c|}{ Nail biting habit } \\
\hline Yes & $287(90.54 \%)$ & $30(9.46 \%)$ & $317(52.83 \%)$ & $>0.05$ \\
\hline No & $255(90.88 \%)$ & $28(9.12 \%)$ & $283(47.17 \%)$ & 1 \\
\hline \multicolumn{5}{|c|}{ Have private toilet } \\
\hline Yes & $514(90.37)$ & $55(9.63 \%)$ & $569(94.83 \%)$ & $>0.05$ \\
\hline No & 30 (96.77\%) & $1(3.23 \%)$ & 31 (5.17\%) & 1 \\
\hline
\end{tabular}

lumbricoide, T. trichiura and H. nana infections (Additional file 1: Table S2).

The overall prevalence of soil transmitted helminthes infection was significantly associated with mother's education. School children with illiterate mother were more infected than school children with University graduate mothers $(p=0.016)$ (Table 2). There was a significant difference in the prevalence of hookworm between boys and girls $(\mathrm{p}=0.041)$ and $A$. lumbricoide $(p=0.037)$ (Additional file 1: Table S3).

\section{Discussion}

The overall prevalence of soil transmitted helminthes was 9.5\%. This result was below the results from Dembia district Northwest Ethiopia, Mizan-Aman, Chencha town and Wolaita Zone, Southern Ethiopia [17-20]. This massive improvement in the prevalence of soil transmitted helminthes might be due to the preventive chemotherapy given to the school children. Therefore, Ethiopia has the chance to achieve the 2020 strategic goals.

Reports from Chencha town Southern Ethiopia have also shown that the individual prevalence of $A$. lumbricoide and T. trichiura was higher than the results of this study [18] and a study from Wolaita zone Southern Ethiopia A. lumbricoide, T. trichiura, E. vermicularis, Taenia spp. and Hookworm was higher than the results of this study. But the result of $H$. nana was similar with this study [17]. Prevalence of helminthes species in Dembia district, Northwest Ethiopia have shown that, A. lumbricoide and T. trichiura infections were higher than this study while hookworm and Taenia species infections were lower than this study [19]. This low prevalence of $A$. lumbricoide and T. trichiura might be due to the control and elimination program given in the study area. Children under the age of 6 years were more infected than children above 6 years. This might be due to younger children have poor personal hygiene since they play in the soil, eat food without washing their hands and put their fingers in their mouth. Similarly, a report from Mizan-Aman town has shown that younger children were more infected with intestinal parasites [20].

With regard to associated risk factors, results from Chencha town Southern Ethiopia the presence of intestinal parasitic infections have statistically significant association with educational status of the household heads and the type of latrine, but in this study only educational status of the households was significantly associated [18]. This may be due to educated mothers may teach their children to practice personal hygiene and environmental sanitation, especially not to play in the soil, hand washing practice before meal and after defecation. A research made in Malasia have shown A school-based health education learning package (HELP) was developed which displayed a significant impact in terms of reducing soil transmitted helminthes infections [21].

Assessment of infection intensity of soil transmitted helminthes in Tanzania have shown that majority of the cases had light to moderate infection intensity, while in this study all of the cases were with light intensity [22]. This implies that one of the strategic goals of the 2020 is achieved in the study area before the expected time. 


\section{Conclusion}

The overall prevalence of soil transmitted helminthes in the study area was low (9.5\%). Of the helminthes species identified, hookworm was the most prevalent helminthes species isolated (4.2\%) followed by $A$. lumbricoide (3\%). All cases of soil transmitted helminthes infections were with light intensity. This might be due to preventive mass chemotherapy given in school children. Educational status of the mother in higher education was protective from soil transmitted helminthes infections.

\section{Limitation of the study}

This study was done among school children and the community was not included as part of the study and the laboratory diagnostic technique used in this study was Kato-Katz. It was better if two laboratory methods and more sensitive laboratory techniques such as molecular techniques and SAF-ether concentration methods were used for the diagnosis of the parasites as the prevalence of soil transmitted helminthes in the study area was low.

\section{Additional file}

Additional file 1. Prevalence of soil-transmitted helminths among school children in Gurage zone Southern Ethiopia (January to December 30, 2017) $(N=600)$.

\section{Abbreviations}

NTDs: neglected tropical diseases; WHO: World Health Organization; SSA: subSaharan Africa; STHs: soil transmitted helminthes; DALYs: disability adjusted life years; epg: egg per gram of stool.

\section{Authors' contributions}

HW was responsible for proposal development, supervision during field work, data analysis and wrote the draft of the manuscript. AW was responsible for supervision during field work and contributed during the writing of the draft of this manuscript. TS initiated the idea for this work and title selection, and provided the necessary information for the design, and guided the design during field work and contributed during the writing of the draft of the manuscript. All authors read and approved the final manuscript.

\section{Author details}

1 Department of Medical Laboratory Science, College of Medicine and Health Sciences, Wolkite University, P.O. Box 07, Wolkite, Ethiopia. ${ }^{2}$ Department of Medicine, College of Medicine and Health Science, Wolkite University, Wolkite, Ethiopia.

\section{Acknowledgements}

The authors would like to extend their deepest appreciation to school teachers and directors of the Gurage zone of the study area for their cooperation, who providing the necessary information for this study. We also like to thank all study participants for their cooperation. We are grateful to thank Wolkite University for funding this research project.

\section{Competing interests}

The authors declare that they have no competing interests.

\section{Availability of data and materials}

The data sets used and/or analyzed during the current study are available from the corresponding author without limitation.

\section{Consent for publication}

Not applicable.

\section{Ethics approval and consent to participate}

This research was done according to the national ethical protocol. Data collection was started after getting ethical clearance from Wolkite University ethical review board. Permission was obtained from Gurage zone academic Office, each Woredas' academic Office and from each school. Written (signed) consent from each participant and guardian was obtained before conducting interviews and sample collection. Data collected from each study participant and results of laboratory tests were kept confidential. Unauthorized person didn't have access to the data.

\section{Funding}

This research was funded by Wolkite University. The funder had no role in study design, data collection and analysis, decision to publish or preparation of the manuscript.

\section{Publisher's Note}

Springer Nature remains neutral with regard to jurisdictional claims in published maps and institutional affiliations.

Received: 7 February 2019 Accepted: 3 April 2019

Published online: 16 April 2019

\section{References}

1. WHO. Progress report on number of children treated with anthelminthic drugs: an update towards the 2010 global target. Geneva: World Health Organization; 2010.

2. WHO. Eliminating soil-transmitted helminthiases as a public health problem in children: progress report 2001-2010 and strategic plan 2011-2020. Geneva: WHO; 2012.

3. Becker SL, Liwanag HJ, Snyder JS, Akogun O, Belizario V Jr, Freeman MC, et al. Toward the $2020 \mathrm{goal}$ of soil-transmitted helminthiasis control and elimination. PLoS Negl Trop Dis. 2018;12(8):e0006606.

4. Luong T. De-worming school children and hygiene intervention. Int J Environ Health Res. 2003;13(sup1):S153-9.

5. Matthys B, Bobieva M, Karimova G, Mengliboeva Z, Jean-Richard V, Hoimnazarova $M$, et al. Prevalence and risk factors of helminths and intestinal protozoa infections among children from primary schools in western Tajikistan. Parasit Vectors. 2011;4(1):195.

6. Donnelly TH, Shergold JH, Southgate PN. Anomalous geochemical signals from phosphatic middle Cambrian rocks in the southern Georgina basin, Australia. Sedimentology. 1988;35(4):549.

7. Deribe K, Meribo K, Gebre T, Hailu A, Ali A, Aseffa A, et al. The burden of neglected tropical diseases in Ethiopia, and opportunities for integrated control and elimination. Parasit Vectors. 2012;5:240.

8. Schwartz MT, Billoski TV. Greenhouse hypothesis: effect on dinosaur extinction. In: Jones BT, Lovecraft NV, editors. extinction. New York: Barnes and Ellis; 1990. p. 175-89.

9. Hotez PJ, Kamath A. Neglected tropical diseases in sub-Saharan Africa: review of their prevalence, distribution, and disease burden. PLoS Negl Trop Dis. 2009;3:8.

10. Tadesse $G$. The prevalence of intestinal helminthic infections and associated risk factors among school children in Babile town, eastern Ethiopia. Ethiop J Health Dev. 2005;19(2):140.

11. Abera B, Alem G, Yimer M, Herrador Z. Epidemiology of soil-transmitted helminths, Schistosoma mansoni, and haematocrit values among schoolchildren in Ethiopia. J Infect Dev Ctries. 2013;7(3):253-60.

12. Grimes JE, Tadesse G, Mekete K, Wuletaw Y, Gebretsadik A, French MD, et al. School water, sanitation, and hygiene, soil-transmitted helminths, and schistosomes: national mapping in Ethiopia. PLoS Negl Trop Dis. 2016;10(3):e0004515

13. Daniel W. A foundation for analysis in the health sciences, 6th ed. Georgia State University; 1995.

14. Tekeste Z, Belyhun Y, Gebrehiwot A, Moges B, Workineh M, Getnet A, et al. Epidemiology of intestinal schistosomiasis and soil transmitted 
helminthiasis among primary school children in Gorgora, Northwest Ethiopia. Asian Pac J Trop Dis. 2013;3(1):61-4.

15. Katz N, Chaves A, Pellegrino J. A simple device for quantitative stool thick-smear technique in schistosomiasis mansoni. Rev Inst Med Trop Sao Paulo. 1972;14(6):397-400

16. Crompton D, Savioli L. Intestinal parasitic infections and urbanization Bull World Health Organ. 1993;71(1):1.

17. Alemayehu B, Tomass Z, Wadilo F, Leja D, Liang S, Erko B. Epidemiology of intestinal helminthiasis among school children with emphasis on Schistosoma mansoni infection in Wolaita zone, Southern Ethiopia. BMC Public Health. 2017;17(1):587.

18. Abossie A, Seid M. Assessment of the prevalence of intestinal parasitosis and associated risk factors among primary school children in Chencha town, Southern Ethiopia. BMC Public Health. 2014;14(1):166.

19. Alemu A, Tegegne Y, Damte D, Melku M. Schistosoma mansoni and soil-transmitted helminths among preschool-aged children in Chuahit,
Dembia district, Northwest Ethiopia: prevalence, intensity of infection and associated risk factors. BMC Public Health. 2016;16(1):422.

20. Jejaw A, Zemene E, Alemu Y, Mengistie Z. High prevalence of Schistosoma mansoni and other intestinal parasites among elementary school children in Southwest Ethiopia: a cross-sectional study. BMC Public Health. 2015;15(1):600.

21. Al-Delaimy AK, Al-Mekhlafi HM, Lim YA, Nasr NA, Sady H, Atroosh WM, et al. Developing and evaluating health education learning package (HELP) to control soil-transmitted helminth infections among Orang Asli children in Malaysia. Parasit Vectors. 2014;7(1):416.

22. Mugono M, Konje E, Kuhn S, Mpogoro FJ, Morona D, Mazigo HD. Intestinal schistosomiasis and geohelminths of Ukara Island, North-Western Tanzania: prevalence, intensity of infection and associated risk factors among school children. Parasit Vectors. 2014;7(1):612.
Ready to submit your research? Choose BMC and benefit from:

- fast, convenient online submission

- thorough peer review by experienced researchers in your field

- rapid publication on acceptance

- support for research data, including large and complex data types

- gold Open Access which fosters wider collaboration and increased citations

- maximum visibility for your research: over $100 \mathrm{M}$ website views per year

At BMC, research is always in progress.

Learn more biomedcentral.com/submissions 